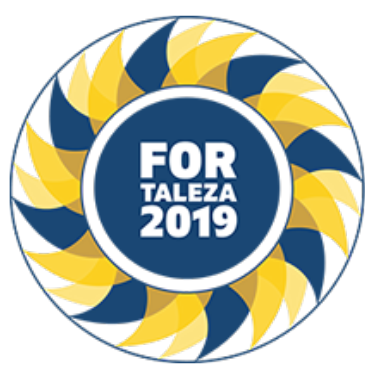

\title{
INCOMPLETE PACHYDERMOPERIOSTOSIS IN YOUNG ADULT: A CASE REPORT
}

Ravena Fontenele Belchior Cabral (Instituto Hospital de Base, Brasilia, DF, Brasil), Francieli Sousa Rabelo (Instituto Hospital de Base, Brasilia, DF, Brasil), Vanessa Fraga Mendes (Instituto Hospital de Base, Brasilia, DF, Brasil), Marina Fernandes Oliveira (Instituto Hospital de Base, brasilia, DF, Brasil)

\section{BACKGROUND}

Pachydermoperiostosis or primary hypertrophic osteoarthropathy (OAH) is a rare genetic disease with probable autosomal dominant inheritance of variable penetrance. It is a syndrome characterized by digital clubbing, periosteosis in the distal diaphyses of the long bones, thickening of the skin of the face and the scalp (pachyderm) and hyperhidrosis. The exact incidence is not known, but the estimated prevalence of the disease is $0.16 \%$. The present case deals with an incomplete form of the disease, characterized by periosteosis without pachydermia.

\section{CASE REPORT}

A 26-year-old male patient, with no prior comorbidities, started pain in the pre-tibial region, with worsening of the efforts and partial improvement with non-hormonal anti-inflammatory drugs. He denied arthritis, smoking, alcoholism or other complaints. At the physical examination, he presented palmoplantar hyperhidrosis and slight wrinkling of the forehead (Figure 1). Among the laboratory tests, inflammatory tests were normal. Radiographs of the lower limbs and upper limbs revealed multiple areas of cortical thickening of the diaphysis of long bones (Figure 2). Bone scintigraphy showed multiple areas of increased osteoblastic activity of long bones (Figure 3). In view of the clinical picture and imaging studies, and exclusion of secondary causes, a diagnosis of pachydermoperiostosis was instituted.

\section{CONCLUSION}

Variations in phenotypic expression result in distinct clinical features; and in a given case, the skin, soft tissues and bones may be involved independently or together. In this case, the radiological picture demonstrating periostosis of long bones associated with clinical hyperhidrosis and mild frontal wrinkling reinforced our diagnostic hypothesis of incomplete pachydermoperiosis. In spite of being a rare pathology, this work highlights the importance of differential diagnosis in a similar clinical context. 